MedieKultur | Journal of media and communication research | ISSN 1901-9726

Editorial

\title{
Media and Civic Engagement
}

\section{Stine Liv Johansen and Cecilie Givskov}

\author{
MedieKultur 2014, 56, 1-4
}

Published by SMID | Society of Media researchers In Denmark | www.smid.dk The online version of this text can be found open access at www.mediekultur.dk

Media are becoming more and more intertwined with all kinds of practices in people's lives - from everyday entertainment to political uprisings around the globe. From a wide range of perspectives, politicians as well as researchers have become aware that media must be taken into account when describing and navigating social movements and developments. The proliferation of digital media stresses questions about the link between, on the one hand, established institutions related to will formation such as the national press and broadcasters and, on the other hand, democracy. New forms of civic engagement are emerging - also among groups that are not usually seen at the forefront of political debate or as relevant from the perspective of national politics or democracy.

This special issue of MedieKultur originated at the biannual meeting of The Association of Media Researchers in Denmark in 2012. Over two days, Danish and international scholars approached the theme from different vantage points and discussed the relevance of these perspectives for media studies in general. Some of the contributions in this issue originate in these discussions; others take an approach from other angles and cases, while new movements and civic engagements appear and make use of media all over the world.

Civic engagement in relation to media can and should be understood in the broadest possible sense. Voters and politicians engage through and with social media, creating new possibilities for political dialogue and dissent. Over the last couple of years, media played a crucial role in the uprisings in the Middle East, and various forms of digital activism are bourgeoning globally. Students use media to enhance their learning of traditional curricula, 
and new fields of learning emerge with media. Cultural production and cultural consumption converge through digital media. People use media as a primary motivating factor in sports and exercise. And consumers, visitors to museums, children, and elderly people are encouraged to engage with brands and cultural institutions as well as each other through media of different sorts.

Like all new media transitions, the digital is ascribed strong transformative powers, contributing either to societal or cultural decline or to increased democratization and enhanced quality of daily life and societal life. Media and communication research is in the process of exploring various elements of these general speculations empirically. It has been our ambition with this issue, as well as the biannual meeting, to contribute to this process by calling for contributions that address a range of different questions. What are the affordances of new and old media in relation to civic engagement? How do different types of media interact with established institutions within civic engagement and the public sphere? How do different media promote the emergence of new user groups and new and/or revitalized engagements? What is the role of media regulation in civic engagement? What are the methodological challenges for research in media and communication?

The submissions in this thematic issue of MedieKultur approach these and similar questions in a wide variety of ways. In general, they represent three different, yet related, perspectives: media at the official, political level of communication, civic and often oppositional communication through and with digital media, and media and communication in culture and everyday life in different arenas such as museums, documentary film, and gaming culture.

The opening article of this journal is Rasmus Kleis Nielsen's "Political communication research: New media, new challenges, and new opportunities". Nielsen's approach takes a 'meta' perspective on political communications research and the challenges it faces in the light of rapid change. It points to a range of theoretical and methodological factors that should be taken into consideration as well as new opportunities for research.

In the article "Online deliberation and beyond? A time-based and comparative study of Danish political debates online", Jakob Linaa Jensen discusses the notion of deliberative democracy compared to online political debates in non-political debate forums. The article expands our understanding of the democratic sphere through empirical analysis of a selection of three very different online debate forums, providing nuance to our conception of what political participation is and how it should be seen in relation to people's everyday life practices.

In line with Linaa Jensen, Cecilie Givskov and Hans Jörg Trenz address the question of new, democratic forms - in this case, the relationship between online political news making and the public sphere. Their article, "Civic engagement through mainstream online newspapers: Possibilities and shortcomings", presents an analysis of the interplay between traditional news media - in online settings - and the facilitation and practice of online debate. The article also sheds new light on the notion of representative democracy. 
In his article "Everyday elites, citizens or extremists? Assessing the use and users of nonelection political hashtags", Anders Olof Larsson focuses on conversations taking place on Twitter by using non-political hashtags as an analytical tool. The article distinguishes between different user groups and places specific emphasis on the so-called top users while also pointing out the need for a much wider range of studies on the structures as well as the practices of online debates.

A very different kind of online debate is presented and discussed in Mattias Ekman's article "The dark side of online activism: Swedish right-wing extremist video activism on YouTube". As the title suggests, this article focuses on a quite specific, oppositional form of online communication through digital media - in this case, YouTube. The democratic potential related to online media is being put into perspective by its counterpart: the nondemocratic activists of the extreme right wing. The potential for democracy is there but so are also many possibilities of communication, which is less oriented towards democracy.

Moving in quite a different direction, Sara Mosberg Iversen focuses on the mundane activities of everyday life media practices - more specifically, the joys and engagements of video games. In the article "Paradox and pleasure: Play with everyday life in The Sims 2 and 3 ", she explores the ambiguities of immersing oneself in gaming activities to escape the chores and obligations of daily life even as the games themselves depict and play out these same everyday routines and trivialities.

Rikke Haller Baggesen, in her article "Augmenting the Agora: Media and civic engagement in museums", describes how public and cultural institutions such as museums are using social media to engage with their customers in new ways. She applies a critical perspective, focusing not only on the potential but also on the limitations and pitfalls of these practices, which may be seen more as a convergence of political and museological objectives with perceived social media affordances than as an actual, improved engagement of the institution with its users.

Finally, Lisbeth Frølunde and Mette Bjerregaard explore how documentary film functions as a hub for different voices related to controversial themes - in this case, mass violence. The article "Re-creating the past for the future: Two film projects about violence - The Act of Killing and Gzim Rewind" analyses how this particular genre can become relevant to processes of social change in societies for which democratic discussion is not to be taken for granted.

This issue contains two articles outside the topic of media and civic engagement, one in Danish and one in English.

In their article "En kvantitativ metode til analyse af radioindhold" ["A quantitative method for analysing radio content"], Christine Lejre and Nete Nørgaard Kristensen address the difficulties of analysing radio due to the fact that this media is neither visual nor based on printed text. The article presents a new quantitative method with specific regard to the medium's modality: sound structured as linear sequences over time. 
In his article "Factors enhancing learning possibilities in digital workshops", Christian Kobbernagel presents a study of processes that support student learning possibilities in digital workshops at art museums in Denmark. The article provides insights into factors enhancing learning possibilities, including the educator's dialogic performance, experiences of art, and the perceived qualities of digital content creation processes in art museum education workshops. The article concludes that the dialogic performance of museum educators, a positive art experience, and positive perceptions of working with digital media are factors that strongly support student participation and reflection.

Stine Liv Johansen Assistant Professor, PhD. Department of Aesthetics and Communication Aarhus University imvslj@dac.au.dk

Cecilie Givskov Assistant Professor, PhD. Department of Media, Cognition and Communication University of Copenhagen cecilieg@hum.ku.dk 